\title{
UN NUEVO ORDEN DE PRIORIDAD EN CASO DE VIOLACIÓN SIMULTÁNEA DE LA CONSTITUCIÓN Y DE LA CARTA DE LOS DERECHOS FUNDAMENTALES DE LA UNIÓN: LA «SUGERENCIA» DE LA CORTE COSTITUZIONALE A LOS JUECES NACIONALES
}

\begin{abstract}
A new priority order in case of simultaneous violation of the constitution and the charter of fundamental rights of the union: the "suggesting" of the Corte Costituzionale to the national judges
\end{abstract}

\author{
SILVIA ROMBOLI \\ Universidad Ramon Llull - ESADE \\ silvia.romboli@esade.edu \\ Cómo citar/Citation \\ Romboli, S. (2020) \\ Un nuevo orden de prioridad en caso de violación simultánea de la Constitución \\ y de la Carta de los Derechos Fundamentales de la Unión: la «sugerencia» \\ de la Corte Costituzionale a los jueces nacionales. \\ Revista Española de Derecho Constitucional, 119, 299-332 \\ doi: https://doi.org/10.18042/cepc/redc.119.10
}

\section{Resumen}

Los efectos directos y la fuerza vinculante de la Carta de los Derechos Fundamentales de la Unión Europea suponen que un número creciente de cuestiones prejudiciales planteadas por los jueces nacionales ordinarios ante el Tribunal de Justicia de la Unión Europea tenga por objeto la interpretación de los derechos fundamental ahí protegidos. El hecho de que la mayoría de los derechos de la Carta estén reconocidos también por las constituciones nacionales puede llevar a que el mismo juez tenga dudas sobre la conformidad de la norma relevante para resolver un caso concreto tanto con la Constitución de su país como con la Carta. El presente trabajo reconstruye en sentido crítico las etapas de la jurisprudencia constitucional 
italiana aplicable a los casos de «doble prejudicialidad» como el descrito. En particular, el artículo se centra en la nueva doctrina de la Corte Constitucional en esta materia inaugurada con la Sentencia 269/2017, y sus trascendentes consecuencias sobre el diálogo entre tribunales.

\title{
Palabras clave
}

Jurisdicción constitucional; diálogo entre tribunales; Carta de los Derechos Fundamentales de la Unión Europea; doble prejudicialidad; Corte Constitucional italiana.

\begin{abstract}
The direct effects of the Charter of Fundamental Rights of the European Union have the consequence that an increasing number of preliminary ruling to the Court of Justice of the European Union is intended to interpret the fundamental rights protected there. The fact that most of the rights of the Charter are also recognized by national constitutions may lead to the same national judge having doubts about the conformity of the relevant norm both with the Constitution of his country and with the Charter. The present work critically reconstructs the phases of Italian constitutional jurisprudence applicable to cases of «double preliminary ruling» as described. In particular, the article focuses on the new doctrine of the Constitutional Court in this matter opened with judgment 269/2017, and its transcendent consequences on the dialogue between courts.
\end{abstract}

\section{Keywords}

Constitutional jurisdiction; inter-court dialogue; Charter of Fundamental Rights of the European Union; double preliminary ruling; Italian Constitutional Court. 


\section{SUMARIO}

I. INTRODUCCIÓN. II. LAS ETAPAS DE LA JURISPRUDENCIA CONSTITUCIONAL ITALIANA EN MATERIA DE «DOBLE PREJUDICIALIDAD»: 1. La primera etapa. 2. La segunda etapa y la Sentencia 269/2017 de la Corte Constitucional: los motivos del «cambio de sentido» en la jurisprudencia constitucional relativa a la doble prejudicialidad. 3. Los contenidos de la Sentencia 269/2017 de la Corte Constitucional italiana. 4. Las reflexiones de la doctrina sobre las consecuencias de los distintos contenidos de la Sentencia 269/2017. 5. El «legado» de la Sentencia 269/2017: alabanzas y críticas a la nueva jurisprudencia de la Corte Constitucional italiana. III. LAS RESPUESTAS DE LAS DISTINTAS JURISDICCIONES ANTE LOS CONTENIDOS DE LA SENTENCIA 269/2017: 1. La respuesta, real o presunta, del Tribunal de Justicia de la Unión Europea. 2. Las respuestas de los jueces nacionales, en particular de la Corte de Casación. IV. LAS PUNTUALIZACIONES DE LA CORTE CONSTITUCIONAL A LA SENTENCIA 269/2017 A TRAVÉS DE SU JURISPRUDENCIA POSTERIOR. V. LAS PERSPECTIVAS ACTUALES RESPECTO DE LAS RELACIONES ENTRE JURISDICCIONES. VI. CONSIDERACIONES CONCLUSIVAS SOBRE LOS EFECTOS DEL NUEVO ORDEN DE PRIORIDAD EN EL DIÁlOGO ENTRE TRIBUNALES. BIBLIOGRAFÍA.

\section{INTRODUCCIÓN}

El progresivo aumento, de un lado, del volumen de producción normativa de la Unión Europea, y, de otro - y como consecuencia del primero-, del número de cuestiones prejudiciales de interpretación y validez del derecho de la Unión Europea (DUE o derecho de la UE, en adelante) ${ }^{1}$ planteadas por las jurisdicciones de los distintos Estados miembros ante el Tribunal de Justicia de la Unión Europea (TJUE) ha acarreado, también, el incremento de los casos de «doble prejudicialidad». La problemática aludida, ya patente en la doctrina desde finales de los años noventa del siglo pasado ${ }^{2}$, se refiere a la

1 Para sustituir las tres palabras y el término, ya obsoleto e incorrecto, "comunitario», la doctrina italiana utiliza un término muy ilustrativo, que podría ser útil también en ocasión de este trabajo: «eurounitario».

2 Cartabia (1997) y Ghera (2000). Más recientemente, en la doctrina española, Cruz Villalón y Requejo Pagés (2015). Ferreres Comella (2011) utiliza la expresión «doble vicio», poniendo el acento entonces en la norma de aplicación al caso concreto, y no en la situación de incertidumbre entre las dos prejudiciales en la que se encuentra el juez nacional respecto de los máximos intérpretes de la validez constitucional y eurounitaria de la norma misma. 
posibilidad de que el juez nacional tenga, en el curso de un proceso, una duda respecto de la norma aplicable y relevante para el caso tanto en relación con su conformidad con la Constitución nacional como respecto de su validez según el derecho de la Unión (o la correcta interpretación de este).

En semejantes casos, el juez tiene que decidir el criterio que seguir y, en último análisis, a cuál de los dos instrumentos (cuestión de inconstitucionalidad o cuestión prejudicial «eurounitaria») dar prioridad (o «precedencia», o incluso "preeminencia», según las expresiones de Cruz Villalón y Requejo Pagés $)^{3}$, o si utilizar los dos de forma simultánea.

La existencia de una situación de «doble prejudicialidad» puede anudarse a la concepción "dualista» que - a pesar del notorio "camino comunitario" recorrido por muchas cortes constitucionales para adecuarse a la posición expresada por el Tribunal de Justicia sobre la relación entre el ordenamiento de la Unión y el interno - sigue caracterizando la concepción de la mayoría de los tribunales constitucionales.

Bajo este concepto, hay ámbitos en los que persiste un cierto margen de control de constitucionalidad para los jueces constitucionales también respecto de las relaciones entre los dos ordenamientos. Dos ordenamientos distintos (y dos órdenes jurisdiccionales cada uno con su Corte como máximo intérprete del primero) pero caracterizados por unas reglas que los vinculan el uno al otro. En particular, la existencia de unas normas que provienen de la Unión Europea y que pueden tener efectos directos o indirectos en el ordenamiento de los Estados miembros. En el primer supuesto (efectos directos), el juez nacional tiene la posibilidad de inaplicar la normativa interna que contravenga el DUE después de plantear una cuestión prejudicial, si lo considerara necesario o estuviera entre los sujetos obligados a este; en el segundo, puede (según el ordenamiento en cuestión) que los tribunales constitucionales ostenten una cierta competencia para apreciar la legitimidad constitucional de la ley por supuesta vulneración del derecho de la UE.

Es difícil negar que la concepción dualista no produzca consecuencias al sobrevenir situaciones en las que se presenta un problema de «doble prejudicialidad». En cambio, en la concepción «monista», propugnada por el Tribunal de Justicia, resulta inevitable que cualquier cuestión sobre el derecho de la UE (aunque presente perfiles de "constitucionalidad») se considere integrada en el juicio sobre la conformidad al DUE ante el Tribunal de Luxemburgo ${ }^{4}$.

Cruz Villalón y Requejo Pagés (2015: respectivamente, 178 y 177).

4 Vecchio (2010: 63 y ss.) afirma que la estrategia dualista ha transformado el diálogo con el juez de Luxemburgo en una suerte de «doble monólogo»; también, véase, sobre este tema, Repetto (2016: 659). 
Sin que quepa analizar en detalle las teorías ofrecidas por la doctrina sobre las diferentes tipologías de "doble prejudicialidad" ${ }^{5}$ y su evolución, el presente trabajo de investigación reconstruye, tanto de forma analítica como en sentido crítico, las etapas recorridas por la jurisprudencia constitucional italiana en su intento de encontrar la mejor fórmula para, de un lado, garantizar la protección más eficaz de los derechos fundamentales de los particulares y, de otro, respetar las obligaciones derivadas del ordenamiento de la Unión Europea.

\section{LAS ETAPAS DE LA JURISPRUDENCIA CONSTITUCIONAL ITALIANA EN MATERIA DE «DOBLE PREJUDICIALIDAD»}

\section{LA PRIMERA ETAPA}

La posición de la Corte Constitucional sobre el tema de la «doble prejudicialidad» y, más en general, de las relaciones entre derecho de la Unión Europea y el derecho interno (de rango legal o constitucional) ha evolucionado considerablemente en los últimos cuarenta años y no siempre de una forma coherente; es más, cabría apreciar, en ocasiones, interpretaciones y posturas incluso contradictorias.

En los años setenta la Corte se limitó a negar su competencia para apreciar la conformidad del derecho comunitario con los principios constitucionales, afirmando que se trataba de una tarea confiada a los jueces ordinarios, a través del instrumento de la cuestión prejudicial ante el Tribunal de Luxemburgo ${ }^{6}$.

En algunas decisiones posteriores ${ }^{7}$, el Constitucional precisó las razones que fundaron la imposibilidad de su intervención. Ante todo, la necesidad de que el juez, al plantear una duda de constitucionalidad, respetara el requisito procesal de la «relevancia». A juicio de la Corte, si un juez planteara una cuestión de inconstitucionalidad que tuviera por objeto una norma interna que, a su entender, pudiera estar en conflicto tanto con la norma fundamental como con el DUE, la resolución de la duda sobre la correcta interpretación del

5 Existirían, en efecto, la «independiente», la «en sentido estricto», la «ampliada», la doble prejudicialidad "con partes invertidas», etc. Véanse, a este respecto, Ghera (2009: 1315 y ss.) y Losana (2014).

6 Auto de la Corte Constitucional, 28 de julio de 1976, n. 206.

7 Para algunas referencias jurisprudenciales, véanse las decisiones citadas en la nota 8 de este trabajo. 
derecho de la Unión sería determinante para establecer la aplicabilidad al caso concreto de la normativa nacional. En efecto, en el supuesto de que la interpretación del TJUE llevara al juez a inaplicar la norma de derecho nacional, ello ocasionaría la irrelevancia de la cuestión desde la perspectiva constitucional, pues la norma ya no sería aplicable al caso. De ahí la necesaria precedencia de la cuestión prejudicial ante el Tribunal de Justicia respecto del planteamiento de una duda de constitucionalidad ante la Corte.

Así pues, el Constitucional, fundándose en lo que algunos han definido como una «artimaña procesal» (Vecchio, 2010: 66), optó por afianzar la competencia del juez ordinario para utilizar el instrumento prejudicial ante el Tribunal de Luxemburgo ${ }^{8}$, evitando, así, una comunicación directa con aquel y, en definitiva, prefiriendo un diálogo con la Corte de Justicia «a través de un intermediario»".

Se alegó que la verdadera razón que fundaba la aludida jurisprudencia constitucional estaba en la voluntad de la Corte Constitucional de evitar encontrarse ante una suerte de doble obligación respecto del Tribunal de Justicia, a saber: de un lado, en relación con el planteamiento de una cuestión prejudicial (obligada, entonces, por ser el juez de «última instancia»), de otro, respecto de las interpretaciones que el TJUE proporcionara y que la Corte Constitucional no habría podido esquivar a la hora de resolver su cuestión de inconstitucionalidad.

Posteriormente, la postura de la Corte se iría modificando paulatinamente hasta llegar a la primera decisión en la que optó por penetrar en el «tentador» diálogo entre tribunales. Se trata del Auto 103/2008 ${ }^{10}$, en el que la

8 Por ejemplo, en determinadas ocasiones, la Corte Constitucional ha decidido devolver las actuaciones al juez a quo porque previamente no se había planteado la cuestión prejudicial al juez de Luxemburgo: pueden verse los autos de la Corte Constitucional de 26 de julio de 1996, n. ${ }^{\circ} 319$, y de 2 de abril de 2009. En otros casos, se ha declarado inadmisible la cuestión de inconstitucionalidad porque al mismo tiempo se había planteado una de validez ante el TJUE (por ejemplo, en el caso del Auto de la Corte Constitucional, de 21 de marzo de 2002, n.o 85), o la emisión de una decisión de este mismo se ha considerado ius superveniens, que justificaba la devolución de las actuaciones al juez a quo (por ejemplo, en el Auto de la Corte Constitucional, 20 de abril de 2004, n. ${ }^{\circ}$ 125). En doctrina, para un análisis detallado sobre esta temática, puede verse Giovannetti y Passaglia (2014: 401 y ss.).

9 El primer autor que utilizó esta expresión (per interposta persona), hoy muy célebre, fue Cartabia (2006: 101-104).

10 Auto de la Corte Constitucional, de 15 de abril de 2008, n. ${ }^{\circ} 103$. Este fue el primer caso en el que la Corte Constitucional planteó una cuestión prejudicial en el ámbito de un recurso de inconstitucionalidad. Posteriormente, con el Auto de la Corte 
Corte admitió su legitimación, reconociéndose como «órgano jurisdiccional» a los efectos del planteamiento de la cuestión prejudicial ante el Tribunal de Justicia según el art. 267 TFUE.

\section{LA SEGUNDA ETAPA Y LA SENTENCIA 269/2017 DE LA CORTE CONSTITUCIONAL: LOS MOTIVOS DEL «CAMBIO DE SENTIDO» EN LA JURISPRUDENCIA CONSTITUCIONAL RELATIVA A LA DOBLE PREJUDICIALIDAD}

La doctrina italiana expresó su perplejidad acerca de las razones que justificaban la precedencia de la prejudicial «eurounitaria» sobre la constitucional, evidenciando cómo se trataba exclusivamente de criterios prácticos de tipo histórico-contingente y de economía procesal (Cerri, 2013: 2897). Algunos autores afirmaron que la falta de participación de la Corte en el diálogo directo con Luxemburgo se debía al preocupante volumen de trabajo que esta debía afrontar (Onida, 2008: 47).

Asimismo, se sostuvo que habría sido preferible «revocar» la preeminencia de la prejudicial ante el TJUE y elegir una situación de «equiordenación» con la constitucional. Debería, así, ser competencia del juez ordinario decidir si plantear antes una u otra, o si hacerlo a la vez (Ghera, 2009: 1315). Incluso se barajó la eventualidad de que el mismo Tribunal de Justicia pudiese pedir a los órganos nacionales que resolvieran antes la cuestión de inconstitucionalidad, pues la eventual ilegitimidad constitucional de la norma aplicable al caso concreto cerraría la puerta a la intervención del juez de Luxemburgo (Malfatti, 2015: 194).

No obstante estas dudas doctrinales, las situaciones de doble prejudicialidad se siguieron resolviendo según las indicaciones de la jurisprudencia consolidada de la Corte Constitucional antes mencionada, que constituía la doctrina comúnmente respetada por los jueces ordinarios, salvo algún desencuentro puntual o esporádico. Solo a finales de 2017 la situación pareció modificarse a partir de una afirmación contenida en una sentencia de la Corte Constitucional, ni siquiera necesaria para la resolución de la cuestión de constitucionalidad y que, por lo tanto, tiene que considerarse un obiter dictum ${ }^{11}$.

Constitucional, de 18 de julio de 2013, n.o 207, la Corte planteó la primera prejudicial con ocasión de una cuestión de inconstitucionalidad.

11 Amalfitano (2019a) afirmó que «sin el riesgo de cometer un error, creo que puede considerarse el [obiter] más comentado en setenta años de jurisprudencia constitucional». En un sentido similar, aunque quizá en términos algo excesivos, véase Morrone 
Los motivos que llevaron a esta modificación son múltiples. Ya antes se ha indicado que la Corte Constitucional, por muchas décadas, había optado por comunicarse con el Tribunal de Justicia «a través de un intermediario», es decir, a través de los jueces ordinarios, reservándose la posibilidad de intervenir en último extremo, esto es, después de que el Tribunal de Luxemburgo ya se hubiera pronunciado, evitando, así, tener que estar sujeta a las interpretaciones de este.

En la práctica, la conexión entre los jueces y el Tribunal de Justicia había funcionado tan bien que la Corte Constitucional no tenía casi nunca la oportunidad de intervenir en el asunto concreto, por lo que no podía participar en ese diálogo.

Como ha subrayado la mayoría de la doctrina, la cuestión prejudicial, tal y como establece el tenor literal del art. 267 TFUE, nació como una herramienta para solicitar la interpretación correcta del derecho de la Unión Europea. Sin embargo, con el tiempo, se ha transformado en un control de la legitimidad de la legislación nacional respecto del derecho de la UE. Un control, por consiguiente, muy similar al ejercido por los tribunales constitucionales para determinar la conformidad de la misma regulación local con las respectivas constituciones nacionales, pero que se realiza en forma de control difuso, dejando al juez la opción de inaplicar o no la regulación nacional después de la (eventual) respuesta del Tribunal de Justicia, y con efectos inter partes, limitados (en muchas ocasiones) al caso concreto ${ }^{12}$.

Asimismo, no hay que olvidar que, siquiera por vía jurisprudencial y no por previsión expresa en los tratados UE, es comúnmente reconocida la eficacia vinculante de la interpretación del Tribunal de Justicia. Así pues, el sistema podría considerarse "semidifuso»" ${ }^{13}$, ya que el juez no es libre de

(2019), autor que afirma que se ha tratado de «un debate que ha llenado las bibliotecas, rompiendo todos los sectores de la cultura jurídica».

12 La doctrina más atenta ha señalado ya desde hace años la realización de un verdadero control de las leyes nacionales por el TJUE, incluso de manera "oculta». Para estas mismas consideraciones, más recientemente, véanse Cruz Villalón y Requejo Pagés (2015: 181), y Catalano (2019: 8).

13 O tal vez «semiconcentrado», dado que el juez nacional tiene la facultad de inaplicar directamente una normativa nacional que considere en contraste con el DUE, pero, cuando este tenga dudas sobre la interpretación correcta del DUE, se le recomienda encarecidamente, o se le obliga (si es el juez de última instancia), solicitar la intervención del TJUE y, posteriormente, seguir la interpretación proporcionada por este último. La transformación de la cuestión prejudicial de un procedimiento de interpretación a una cuestión relativa a la conformidad de la legislación nacional con el DUE produce una real concentración de dicho control en las manos del TJUE, 
inaplicar o no, sino que está sujeto a la decisión europea. Sobre los efectos solo inter partes, todos los jueces, en las mismas condiciones, están obligados a seguir la interpretación del juez de Luxemburgo, especialmente si la respuesta es precisa y puntual sobre una normativa concreta y un caso específico ${ }^{14}$.

La transformación de la cuestión prejudicial fundamenta, a todas luces, el "cambio de sentido" (o punto de inflexión) representado por la Sentencia 269/2017 de la Corte Constitucional ${ }^{15}$. En efecto, a raíz de esta metamorfosis, los jueces nacionales habían hecho cada vez más un uso extensivo de la noción de «derecho fundamental», desatendiendo o interpretando de forma restrictiva la limitación que deriva del art. 51.1 de la Carta de los Derechos

aunque, en ciertos casos, estemos en presencia (formalmente) de una inaplicación del juez nacional con efectos solo para el juicio concreto.

14 Gallo (2019: 225) denomina el europeo un "sistema concentrado», ya que solo el Tribunal de Justicia puede interpretar de manera definitiva y con eficacia vinculante el derecho de la Unión Europea.

15 Sentencia de la Corte Constitucional, de 14 de diciembre de 2017, n. ${ }^{\circ} 269$. Pueden verse los numerosos comentarios en la página web https://bit.ly/2Znr $7 \mathrm{uO}$.

La decisión, que se analizará a continuación, se definió como «la novedad jurisprudencial más significativa respecto de las relaciones entre el Derecho interno y el Derecho de la Unión Europea después de la sentencia núm. 170 de 1984 que [...] introdujo el control difuso de "no aplicación" de la regulación interna incompatible con aquella comunitario» (Scaccia, 2018a: 1; y también Vernuccio, 2018: 2). Otros autores la definieron como un "cambio de sentido» histórico (Ruggeri, 2017) de una importancia potencialmente «épica» (Repetto [2017: 2955] utiliza el término italiano «epocale»), o, en fin, como una «desviación del modelo» (Mastroianni, 2018: 22). Para otros comentaristas, dicha resolución pudiera considerarse casi un «acto de guerra» contra los jueces ordinarios y la casación, en particular debido a la voluntad de la Corte Constitucional de romper el estrecho vínculo que los jueces habían venido estableciendo, a través de la cuestión prejudicial, con el Tribunal de Luxemburgo. De esta opinión, entre otros, Morrone (2019), según el cual la actividad dialógica de los jueces nacionales y el Tribunal de Justicia «se ve interrumpida» por la pretensión de la Corte Constitucional de establecer una interpretación y aplicación conforme del derecho europeo con la protección de los derechos fundamentales establecidos por la Constitución respecto de aquella prevista por la Carta DFUE. En este sentido, también, Conti (2017a: 12 y ss.), Vitale (2019: 3) y Gallo (2019: 231).

Otra doctrina prefirió hablar de una toma de postura soberanista: entre otros, Caruso (2017: 3) y también Morrone (2019). En opinión de Massa (2019), sin embargo, la Sentencia 269/2017 no se funda ciertamente en un «resurgimiento extemporáneo de soberanismo", sino, más bien, en "la intención de la Corte constitucional de preservar su papel y ser parte activa de esa realidad que se ha descrito como el "laboratorio jurisprudencial de los derechos fundamentales protegidos a nivel europeo"». 
Fundamentales de la Unión Europea (en adelante: Carta o CDFUE), que especifica su ámbito de aplicación de acuerdo con el principio de subsidiariedad y, exclusivamente, en la aplicación del derecho de la Unión ${ }^{16}$.

La utilización de la cuestión «eurounitaria»y, por ende, la estrecha y frecuente relación entre los jueces nacionales y el Tribunal de Justicia en materia de derechos fundamentales han llevado a la Corte Constitucional a una situación que se ha definido como «desecación»o «desecamiento» de las competencias que a esta le reconoce la Constitución ${ }^{17}$. Como consecuencia se ha apreciado la reducción del papel ejercido por la Corte a través del control de las leyes en vía incidental, lo que ha conllevado una suerte de apartamiento de esta, se podría decir «forzoso», en la protección de los derechos fundamentales. Esto acarrea el riesgo de que el juez constitucional sea visto como frío y distante «juez de los poderes» en lugar de un eficaz guardián de los derechos ${ }^{18}$.

Otras dos razones que han sido identificadas por la doctrina como presupuestos de la innovadora Sentencia 269/2017 están vinculadas a acontecimientos más recientes. La primera es el reconocimiento, a la luz del Tratado de Lisboa, del valor vinculante y eficacia directa de la Carta de los DFUE, es decir, el mismo valor que los tratados constitutivos de la Unión Europea ${ }^{19}$.

La segunda alude a la decisión de la Corte Constitucional de entrar a formar parte de los sujetos legitimados para proponer ex art. 267 TFUE cuestiones prejudiciales ante el Tribunal de Luxemburgo ${ }^{20}$. Tras un largo período de tiempo en el que la Corte se negó expresamente a esta posibilidad, cambió de criterio y propuso una cuestión, en $2008^{21}$, en el ámbito de un recurso de inconstitucionalidad, y, posteriormente, en 2013, con ocasión de un control incidental $^{22}$. Si la falta de legitimación del juez constitucional justificaba la atri-

16 En este sentido se expresaron, entre otros, Leone (2020), Piccone (2018: 327) y Cozzi (2018: 14).

17 Entre otros, Barbera (2018) ha utilizado estos términos. Conti (2018: 283 y ss.) ha afirmado que la opción preferente del juez por la cuestión ante el TJUE obedece también a otro motivo: la prejudicial comunitaria (o europea) resulta ser una ayuda fundamental para el juez que no modifica, en muchas ocasiones, su capacidad en la toma de decisiones; sin embargo, la cuestión de inconstitucionalidad priva al remitente del poder de decidir sobre el objeto de la cuestión sometida al análisis de la Corte.

18 Scaccia (2018a: 6) y Anzon (2018: 1). Romboli, R. (2017: 35 y ss.) ha definido este fenómeno como "crisis de la cuestión incidental de constitucionalidad de la ley».

19 Evidencian este elemento en cuanto fundamento de la doctrina contenida en la 269/2017 también Scaccia (2018a: 9 y ss.) y Tega (2019: 10).

20 De esta opinión, entre otros, Romboli, R. (2018: 7).

21 Auto de la Corte Constitucional, de 15 de abril de 2008, n.o 103.

22 Auto de la Corte Constitucional, de 18 de julio de 2013, n. 207. 
bución exclusiva a los jueces ordinarios de la tarea de plantear las cuestiones ante el Tribunal de Justicia, este cambio jurisprudencial abrió, al menos en parte, la posibilidad de un diálogo directo entre los dos altos tribunales ${ }^{23}$.

\section{LOS CONTENIDOS DE LA SENTENCIA 269/2017 DE LA CORTE CONSTITUCIONAL ITALIANA}

Nótese que, en el caso concreto que dio lugar a la paradigmática Sentencia 269/2017, una de las partes pidió al juez encargado de resolverlo que procediera inaplicando la legislación nacional ${ }^{24}$ contraria a una normativa $\mathrm{UE}^{25}$. Sin embargo, el juez a quo consideró que la normativa nacional aplicable podía entrar en contradicción con determinadas disposiciones constitucionales y, sin entrar a valorar en ningún momento su compatibilidad con el DUE, decidió plantear una cuestión de inconstitucionalidad ante la Corte Constitucional. No se trataba en puridad, pues, de un caso de eventual «doble prejudicialidad». No obstante, la Corte aprovechó la oportunidad para proporcionar dos aclaraciones sobre los límites dentro de los cuales el juez debe considerarse obligado a dar prioridad al planteamiento de una cuestión prejudicial ante el Tribunal de Justicia, so pena de declarar inadmisible la cuestión de constitucionalidad (como venía exigiendo la jurisprudencia constitucional hasta ese momento).

La primera aclaración parece hacerse con el único propósito de recordar a los jueces el respeto de los límites dentro de los cuales es posible, y en algunos casos obligatorio, pedir la intervención del Tribunal de Luxemburgo. En tal sentido, la Corte reitera su criterio consolidado: el contraste de la norma interna con el DUE afecta a la relevancia de la cuestión de inconstitucionalidad y, por tanto, en caso de doble duda — de conformidad del derecho interno, de un lado, con la Constitución, y, de otro, con el DUE- debe resolverse con carácter prioritario el segundo, solo cuando el derecho eurounitario tiene directa aplicabilidad; por lo contrario, ante el derecho de la Unión sin efectos directos, el juez ordinario tendrá que plantear primeramente una cuestión de inconstitucionalidad.

En todo caso, la puntualización, por así decir, «revolucionaria» es la segunda, que pretendo sintetizar descomponiéndola en cinco puntos o afirmaciones.

23 Del mismo parecer, entre otros, Barbera (2018), Amalfitano (2019a) y Tega (2019).

24 En concreto, se trataba de la Ley 287/1990, de 10 de octubre (Norme per la tutela della concorrenza e del mercato), modificada por la Ley 27/2012, de 24 de marzo.

25 Véase, a este propósito, el antecedente 4.2. 
Primero (a): la CDFUE no puede compararse con el «normal» derecho de la Unión, sino que «tiene características peculiares debido a su contenido típicamente constitucional $»^{26}$. Los principios y derechos establecidos en la Carta se entrelazan en gran medida con los principios y derechos garantizados por la Constitución. Por consiguiente, es posible que el juez se enfrente a una violación conjunta de ambos textos.

Segundo (b): las violaciones de los derechos fundamentales de la Constitución y de la Carta demandan la necesidad de una intervención erga omnes de la Corte constitucional, debido al papel que asume el control concentrado como base de la «arquitectura constitucional $»^{27}$.

Tercero (c): la Corte Constitucional juzgará a la luz de los parámetros constitucionales y europeos (en aplicación de los art. 11 y 117.1 de la Constitución italiana), «también para asegurar que los derechos garantizados por la Carta se interpreten en armonía con las tradiciones constitucionales, a las que se refieren los artículos 6 TFUE y 52.4 de la Carta ${ }^{28}$.

Cuarto (d): en el caso de una ley que se considere contraria tanto a la Constitución como a la Carta "dentro del ámbito de relevancia comunitaria», debe plantearse la cuestión de legitimidad constitucional; la Corte precisa, no obstante, que el juez ordinario tendrá la posibilidad de dirigirse al TJUE con una cuestión de interpretación o validez en caso de que tenga una duda sobre el DUE, de conformidad con el art. 267 TFUE y con la jurisprudencia del TJUE.

Quinto (e): en estas coordenadas, la prioridad del control de constitucionalidad no estaría en contradicción con el DUE, tal como lo interpreta el Tribunal de Justicia. A este respecto, la Corte cita la respuesta dada por el TJUE al recurso del Tribunal de Casación francés respecto de la introducción de la cuestión de inconstitucionalidad en el sistema de justicia constitucional francés $\mathrm{y}$, en particular, del problema de la priorité constitutionnel ${ }^{29}$.

\footnotetext{
Fundamento jurídico 5.2.

Fundamento jurídico 5.2 .

Fundamento jurídico 5.2.

9 Sobre la reforma del sistema de justicia constitucional francés y el problema de la denominada prioridad constitucional puede verse, entre otros, Catalano (2016). Respecto, en particular, de la "question prioritaire de constitutionnalitè», véase Rousseau (2012).

En Austria, la Corte Constitucional consideró la Carta como un posible parámetro de control para la cuestión de inconstitucionalidad, con la consiguiente obligación para el juez de plantearla en caso de conflicto entre la Carta y la legislación nacional. Sin embargo, los poderes del juez se han delimitado, pues la prioridad constitucional es configurable solo cuando el contenido de la garantía de la Carta es similar en el
} 
Recuérdese que, en aquella ocasión, el Tribunal de Luxemburgo consideró que la ley francesa no entraba en conflicto con el art. 267 TFUE, pero solo si se respetaban tres condiciones, siendo la tercera de estas que los órganos jurisdiccionales nacionales debían seguir siendo libres de «inaplicar, una vez haya acabado dicho procedimiento [el ante el Conseil constitutionnel], la disposición legislativa nacional en cuestión, si la consideraban contraria al DUE» ${ }^{30}$.

Una extraña forma de proceder, en cualquier caso, no pasó desapercibida a los comentaristas: si bien las dos primeras declaraciones de la STJUE de 2010 se citan entre comillas y manteniendo el texto original, la Corte Constitucional manipula la tercera (que es la que tiene más trascendencia para el tema de la doble prejudicialidad) mediante la introducción de la expresión «por otras razones» ${ }^{31}$. Así pues, en la Sentencia 269/2017, la tercera condición presenta este enunciado: los jueces son libres de «inaplicar, una vez que haya acabado el juicio incidental de constitucionalidad de la ley, la disposición legislativa nacional en cuestión que haya superado el control de constitucionalidad si, por otras razones, la consideran contraria al DUE» ${ }^{32}$.

propósito y en la formulación literal a los derechos garantizados por la Constitución. Para referencia a la experiencia austriaca, véanse Vernuccio (2018: 13 y ss.) y Scaccia (2018a: 14).

30 STJUE, Gran Sala, de 22 de junio de 2010, asunto Melki. En doctrina puede consultarse Marti (2010).

Las otras dos condiciones son las siguientes: a) la libertad de los jueces «de poder plantear ante el Tribunal de Justicia cualquier cuestión prejudicial que consideren necesaria en cualquier etapa del proceso que consideren apropiado y también después de un procedimiento de control incidental de legitimidad constitucional», y b) «adoptar las medidas necesarias para garantizar la protección jurisdiccional provisional de los derechos reconocidos por el ordenamiento jurídico de la Unión». Esta doctrina fue posteriormente reiterada y confirmada; puede verse, por ejemplo, la STJU, sección V, de 11 de septiembre de 2014, asunto $A$ c. B y otros.

31 Fundamento jurídico 5.2: «[...] di disapplicare, al termine del giudizio incidentale di legittimità costituzionale, la disposizione legislativa nazionale in questione che abbia superato il vaglio di costituzionalità, ove, per altri profili, la ritengano contraria al diritto dell'Unione».

32 Evidencian, específicamente, esta peculiaridad Romboli, R. (2018: 223), que observa que, «en lugar de un sutil juego de comillas y manipulación del texto, hubiera sido deseable, dada la importancia que asume aquella modificación, que la Corte constitucional hubiera proporcionado una justificación para su elección y establecido unos límites para el juez en caso de emitir una sentencia que declare la constitucionalidad de la ley en cuestión», y también Catalano (2019) y Tega (2019); mientras que el magistrado constitucional Viganò (2019) denuncia la modificación hablando de una «ambigüedad lexical». 


\section{LAS REFLEXIONES DE LA DOCTRINA SOBRE LAS CONSECUENCIAS DE LOS DISTINTOS CONTENIDOS DE LA SENTENCIA 269/2017}

La doctrina se ha interrogado sobre el significado y las posibles consecuencias de las puntualizaciones de la Corte de las que se acaba de dejar constancia.

Respecto de la primera (sub a), algunos autores han señalado que la excepción que el Constitucional añade en la Sentencia 269/2017 a la regla general debe considerarse válida solo para los casos en los que los jueces nacionales sospechen que la norma nacional pueda entrar en conflicto tanto con los derechos de la Carta como con los de la Constitución ${ }^{33}$ y siempre que se trate del mismo derecho ${ }^{34}$. A este respecto, se ha planteado el interrogante de si hay que referirse a la Carta en un sentido formal, esto es, únicamente a las disposiciones allí contenidas o, por lo contrario, también a las normas UE que la desarrollan ${ }^{35}$.

Otra duda es aquella relativa a si la nueva jurisprudencia puede referirse a las disposiciones de los tratados sin eficacia directa que establezcan derechos o libertades, argumentando que la diferencia en el tratamiento podría basarse en la diferencia entre las categorías de derechos. Para algunos autores los derechos contenidos en los tratados son "principios de estructura», esenciales para el mercado común, de modo que necesitarían el máximo grado posible de reconocimiento uniforme en toda la Unión, siendo, por lo tanto, necesario que sigan sometidos a un control de tipo difuso por parte del TJUE (Scaccia, 2018a: 10).

Si la doctrina mayoritaria ha evidenciado la importancia de una decisión con efectos erga omnes y, por ende, la necesidad de la intervención de la Corte constitucional en materia de derechos y libertades $(\mathrm{sub} b)^{36}$, la referencia a las tradiciones constitucionales (sub c) ha dado lugar a importantes controversias. Algunos autores consideran que la función de intérprete de la Carta corresponde al Tribunal de Justicia, criticando consiguientemente la afirmación de la

33 Comazzetto (2018: 20), según el cual, como consecuencia, se tendrán que excluir: a) las normas de aplicación directa contenidas en actos distintos de la Carta (por ejemplo, derechos — libertad de establecimiento y libre prestación de serviciosgarantizados directamente por los tratados), y b) los derechos directamente aplicables establecidos solo en la Carta (supuestos que, en realidad, son difíciles de identificar, y que introducen una distinción poco oportuna dentro de los derechos reconocidos por la Carta).

34 En este sentido, por ejemplo, Leone (2020).

35 Se refieren a este problema Cozzi (2018: 16), Repetto (2017: 2959-2960) y Ruggeri (2017: 10-12).

36 Por ejemplo, Barbera (2018) y Viganò (2019). 
Corte Constitucional ${ }^{37}$. Otros, con mejor criterio a mi juicio, entienden que, con la referencia a la interpretación de la Carta en armonía con las tradiciones constitucionales nacionales, la Corte Constitucional no quiso afirmar la facultad de interferir en una tarea (la interpretación de la Carta) que ciertamente pertenece al Tribunal de Justicia, sino que, más bien, procura evitar que esta actividad se realice exclusivamente por los jueces nacionales y el Tribunal de Luxemburgo, sin ninguna participación de la Corte Constitucional ${ }^{38}$.

Creo más exactamente que, en lo que concierne a los derechos reconocidos en la Carta y no relacionados con el mercado común, la intervención prioritaria de la Corte Constitucional tiende a preservar la identidad constitucional del país ${ }^{39}$, ya que puede ofrecer al Tribunal de Justicia los elementos necesarios de conocimiento del derecho nacional, útiles para resolver el caso y para identificar las tradiciones constitucionales que pueden formar parte de las calificadas "comunes» ${ }^{40}$.

Recientemente se ha argumentado, siguiendo a Häberle, que, en el momento actual del constitucionalismo, las constituciones nacionales solo pueden ser "constituciones parciales», por lo que su papel tiene que modificarse, al menos parcialmente, a tenor no tanto de su supremacía jerárquica, cuanto de su capacidad para adaptarse a un determinado marco de valores materiales compartidos. La identidad política y cultural de un país es un elemento que debe tomarse en consideración en la formación de las «tradiciones constitucionales comunes» y, con este propósito, el papel que los jueces nacionales y, en particular, los tribunales constitucionales están llamados a jugar, en sus relaciones con las jurisdicciones europeas, es fundamental ${ }^{41}$.

Por lo que atañe a la necesaria prioridad del control constitucional (sub d), dentro de los límites mencionados, la mayoría de la doctrina ha visto en ella la indicación de una conducta obligatoria para el juez y, por consiguiente,

37 De esta opinión, Conti (2017b: 21); Rossi (2018: 6-7) afirma que ningún tribunal constitucional puede reservarse el poder de interpretar la Carta, incluso con el propósito de armonizarla con sus propias tradiciones constitucionales, porque es solo a través del diálogo con el Tribunal de Justicia que los valores de la Constitución pueden elevarse a tradiciones constitucionales comunes; el juez constitucional puede interpretar la Constitución a la luz de la Carta, pero no al revés.

En este sentido puede verse Comazzetto (2018: 30).

39 Véase, a este propósito, Scaccia (2018a: 10).

40 De este parecer es también Anzon (2018: 6), que afirma que esto no representaría una "soberanía de los derechos», sino la presencia de dos ordenamientos autónomos entre sí, pero coordinados y comunicantes.

41 Romboli, R. (2020), y los autores allí citados. 
ha subrayado la naturaleza preceptiva del obiter, considerando que tal decisión entra dentro de las competencias de la Corte en los sistemas concentrados de control de la legitimidad de las leyes. Otros han sostenido, sin embargo, la libertad absoluta del juez a la hora de elegir entre plantear una cuestión de inconstitucionalidad o la prejudicial ante el Tribunal de Justicia y, en último extremo, inaplicar la norma nacional en contradicción con la Carta (y con la Constitución) $)^{42}$.

Si se quiere optar por la obligatoriedad de las afirmaciones contenidas en el obiter de la Corte, es oportuno preguntarse qué instrumentos tiene a disposición la jurisdicción constitucional para garantizar que los jueces nacionales sigan la nueva regla. Existe, ciertamente, la facultad de activar los procedimientos de responsabilidad civil contra aquellos jueces que no cumplan el mandato de la Corte, o de plantear un conflicto entre poderes del Estado ante el mismo Constitucional; o, incluso, la posibilidad de las partes de alegar ante el Tribunal de Justicia la necesaria inadmisibilidad de la cuestión prejudicial planteada por el juez a quo por desatención del obiter dictum ${ }^{43}$.

Finalmente, por lo que respecta al último presupuesto analizado (sub e), esto es, la compatibilidad del obiter dictum con la jurisprudencia del Tribunal de Justicia, la atención de la doctrina se ha centrado en el sentido de la expresión "por otras razones» que fue introducida por la Corte Constitucional al exponer la doctrina del TJUE sentada en el caso Melki.

La interpretación más plausible es que la Corte quisiera evitar que el juez, después de haber planteado la cuestión de inconstitucionalidad y si esta hubiera terminado con una declaración de constitucionalidad de la norma enjuiciada, pudiera inaplicarla por entrar en conflicto con el DUE, aduciendo las mismas razones por las cuales la Corte hubiera excluido la contradicción de la norma interna con la Constitución y con la Carta. Semejante limitación a los poderes del juez nacional estaría ciertamente en conflicto con la jurisprudencia del Tribunal de Justicia, expuesta precisamente a través de aquella decisión que la Corte Constitucional cita, aun trastocando su texto. En tales circunstancias, la doctrina ha proporcionado multitud de posibles interpretaciones alternativas para evitar que la jurisprudencia de la Corte entre en conflicto con la de Luxemburgo. Convence, especialmente, la tesis según la cual no existiría ningún impedimento, después de la eventual sentencia de la Corte, para una cuestión ante el Tribunal de Justicia; la frase «sospechosa» debe entenderse en el sentido de que el juez no puede puentear la sentencia constitucional e inaplicar la normativa en cuestión, sino que es

42 Puede consultarse, por ejemplo, Ruggeri (2019a: 601).

43 Para el análisis de estas posibilidades, Scaccia (2018a: 13-14). 
necesario que pida la intervención del Tribunal de Justicia (siempre que la Corte Constitucional no haya planteado por sí misma una cuestión prejudi(ial $)^{44}$. La frase añadida por la Corte, además, expresaría la voluntad de esta de formar parte desde un primer momento del diálogo, pero no excluye la posibilidad de que se presente posteriormente una decisión con contenido diferente por parte del TJUE y, en suma, que el juez tenga que seguir las indicaciones del segundo (Tega, 2018a: 4-5). El Constitucional habría querido reclamar el derecho a una "primera palabra», no a la última.

\section{EL «LEGADO» DE LA SENTENCIA 269/2017: ALABANZAS Y CRÍTICAS A LA NUEVA JURISPRUDENCIA DE LA CORTE CONSTITUCIONAL ITALIANA}

Aun reconociendo el valor histórico, casi revolucionario, de la Sentencia 269/2017, una parte de la doctrina no se ha resistido a ponerla en cuestión. Se ha dicho, así, que con esta decisión la Corte Constitucional excluiría la posibilidad de que el juez ordinario pueda buscar soluciones diferentes para los muchos, y muchas veces distintos, casos que se le presentan, en particular respecto de aquellos casos en los que aparecen concernidas disposiciones de una Carta de contenido constitucional, desplazando el eje central de la protección de los derechos a la Corte Constitucional como el único y más fiable intérprete nacional de la Carta, en detrimento de los jueces ordinarios, considerados inadecuados por sí solos para desempeñar esta tarea (Conti, 2017b: 22 y ss.).

La primacía de la Constitución equivaldría a mantener la Carta de los DFUE desprovista de valor normativo respecto de los jueces ordinarios con el objetivo de atribuir a la Corte Constitucional la interpretación y aplicación de las normas de la Carta. Así visto, la Sentencia 269/2017 marcaría un paso atrás respecto a la sentencia Granital ${ }^{45}$, con la finalidad de concentrar todos

44 Comazzetto (2018: 25 y ss.). En las conclusiones, afirmaré que esta sería, en mi opinión, la solución más adecuada y deseable y que mejor realizaría una protección eficaz de los derechos fundamentales que tenga en cuenta tanto las tradiciones constitucionales nacionales como la necesidad de una aplicación homogénea del DUE. La efectiva realización de este sistema multinivel (no en sentido jerárquico) de protección de los derechos pasaría, así, a través de un real diálogo entre tribunales, en el que es absurdo que las cortes constitucionales queden al margen.

Pueden verse, también, las propuestas de Randazzo (2018: 371 y ss.) y Scaccia (2018b: 6).

45 Sentencia de la Corte Constitucional, de 8 de junio de 1984, n. 170. 
los poderes de control en manos de la Corte Constitucional y con la consecuencia última de que el DUE volvería a estar sujeto no solo a los contralímites, sino a todas las disposiciones constitucionales (Morrone, 2019).

El obiter dictum, en definitiva, podría representar la afirmación de la prevalencia axiológica de la Constitución y el síntoma de la desconfianza hacia la Unión Europea, que podría poner en dudas la autoridad del Tribunal de Justicia y debilitar el proceso de integración europea ${ }^{46}$.

No obstante, no puede negarse el doble impacto positivo del obiter dictum: de un lado, el "cambio de sentido" acometido por la Corte constitucional italiana trataría de llevar la garantía de los derechos fundamentales al amparo de la jurisdicción constitucional, sustrayéndola a una inmediata inaplicación de la ley nacional por parte de los jueces ordinarios, y, de otro, crearía un procedimiento que ofrece al Tribunal de Justicia los elementos necesarios para conocer el derecho nacional útil para la resolución de la cuestión concreta y, sobre todo, para la identificación de las tradiciones constitucionales comunes ${ }^{47}$.

No faltan, para concluir, autores con los cuales coincido, que entienden que no hay que atribuir un valor excesivo al célebre obiter dictum de la 269/2017; sería más razonable no sobredimensionar su alcance y valor. La posición anterior y, podría decirse, tradicional de la Corte Constitucional con respecto al problema de la doble prejudicialidad, en efecto, se ha visto confirmada con la primera de las matizaciones analizadas. El obiter podría verse, como mucho, como una «derogación» (Romboli, R., 2018: 2231) o una «excepción» (Leone, 2020) a una jurisprudencia bien consolidada. Una excepción que alude solo al supuesto de que la doble prejudicialidad esté ligada a la violación conjunta de las disposiciones de la Constitución y de la Carta, ni más ni menos. En tal supuesto, la Corte sugiere a los jueces que, primero, utilicen la cuestión de inconstitucionalidad, para que ella pueda, en su caso, declarar la inconstitucionalidad de la norma con eficacia erga omnes, aunque tal sugerencia no tenga ningún valor vinculante para los jueces, ni acarree sanción ninguna su inobservancia.

La regla según la cual el juez debe dirigirse de manera prioritaria al Tribunal de Justicia (reiterada en la 269/2017 con la «excepción» aludida) se funda, como es sabido, en una interpretación de la Corte que encuentra su sentido, como también sucede en Espańa, en el requisito de la relevancia de la norma objeto del control incidental de constitucionalidad. La observancia de este requisito por parte de los jueces está garantizada a través de la

46 Entre otros, Amalfitano (2019b: 32-34).

47 De este parecer, por ejemplo, Anzon (2018: 5-6). 
decisión de inadmisibilidad; en todos los supuestos en los que un juez, sin respetar esa condición, recurriese antes a la Corte constitucional, esta declararía la cuestión inadmisible e invitaría el juez a acudir, primero, al Tribunal de Luxemburgo. Es evidente que la Corte Constitucional no tiene ningún instrumento a su alcance para obligar al juez ordinario a respetar la indicación contenida en la Sentencia 269/2017, pues no puede evitar que los órganos jurisdiccionales nacionales planteen una cuestión prejudicial ante el TJUE, o inapliquen una norma nacional que consideren contraria a una disposición directamente aplicable de la Carta. Por consiguiente, pese a que la Corte Constitucional en la 269/2017 se exprese incuestionablemente en términos de "deber del juez», en realidad su afirmación tiene que calificarse como una simple «invitación ${ }^{48}$, una sugerencia no vinculante para ese juez, que puede o no aceptarla.

No es apropiado, en suma, recurrir a remedios extraordinarios ${ }^{49}$; más bien es deseable que la relación entre los jueces ordinarios y la Corte Constitucional se funde en una colaboración voluntaria, en la aceptación por parte de los órganos jurisdiccionales de la «sugerencia» del Constitucional no porque esta se imponga, sino porque se comparten sus fundamentos; es decir, que esta decisión del juez esté tomada, como se ha afirmado, no por respeto a la autoridad de la Corte, sino, por lo contrario, por la convicción real de que la vía indicada por el Constitucional es la apropiada (Viganò, 2019).

\section{LAS RESPUESTAS DE LAS DISTINTAS JURISDICCIONES ANTE LOS CONTENIDOS DE LA SENTENCIA 269/2017}

\section{LA RESPUESTA, REAL O PRESUNTA, DEL TRIBUNAL DE JUSTICIA DE LA UNIÓN EUROPEA}

La intensa reacción doctrinal provocada por la Sentencia 269/2017 ha alertado, por así decir, de los eventuales efectos negativos que dicha resolución habría podido tener en el contexto del denominado «diálogo entre tribunaless ${ }^{50}$. Con todo, para evaluar realmente esos posibles efectos ha sido necesario esperar a la concreta reacción suscitada en cada uno de los niveles jurisdiccionales, incluido el constitucional.

\footnotetext{
Entre otros, Romboli, R. (2018).

Como los aludidos en las páginas anteriores, nota 43

50 Muchos han sido los trabajos dedicados al tema del «diálogo entre tribunales». Puede citarse, por ejemplo, el de Saiz Arnaiz (2017).
} 
Respecto de las relaciones entre la Corte Constitucional y el Tribunal de Justicia, se aludió al «riesgo de una nueva ronda belicosa en las relaciones con el Tribunal de Justicia de la Unión $»^{51}$. Lo cierto, en todo caso, es que, hasta la fecha, el Tribunal de Luxemburgo no ha tenido la oportunidad de expresarse sobre la nueva jurisprudencia de la Corte. Y ello por cuanto, aunque se haya sugerido ${ }^{52}$, ningún juez ha planteado explícitamente una cuestión prejudicial con el objeto de preguntar al TJUE la conformidad de las afirmaciones contenidas en la Sentencia 269/2017 con el derecho de la Unión. Alguna doctrina sí que ha visto referencias implícitas a esta jurisprudencia en dos sentencias recientes. Una, la sentencia con la que el Tribunal de Justicia $a^{53}$ resolvió una cuestión prejudicial planteada por el Consejo de Estado italiano ${ }^{54}$ y, otra, la sentencia del TJUE de la Gran Sala, de 24 de octubre de 2018, asunto XC, YB y ZA c. Austria.

Sin embargo, a mi juicio, ambas resoluciones no pueden leerse como respuestas indirectas a la posición de la Corte. La primera de ellas fue emitida solo seis días después de la 269/2017, de modo que, como ha afirmado también Amalfitano (2019b: 34), su texto ya había sido aprobado antes de la publicación de la sentencia italiana. En cuanto a la segunda, el TJUE no añade nada nuevo a su anterior jurisprudencia en materia de doble prejudicialidad, reiterando casi exactamente lo expresado en la clásica sentencia de 9 de marzo de 1978 del caso Simmenthal.

\section{LAS RESPUESTAS DE LOS JUECES NACIONALES, EN PARTICULAR DE LA CORTE DE CASACIÓN}

Más allá del ámbito supranacional, los tribunales internos sí que han tenido ocasión de reaccionar frente a las «sugerencias» de la Corte.

Ya se ha dicho que el control difuso (o semidifuso) del DUE por parte de los jueces ordinarios, en estrecha colaboración con el Tribunal de Justicia a través de la cuestión prejudicial, se había consolidado en Italia en una realidad en la que el juez nacional disponía de un amplio margen de apreciación; la misma Corte Constitucional, en efecto, exhortó a los jueces a establecer una relación directa con el Tribunal de Justicia sin tener que pasar por ella misma ${ }^{55}$.

\footnotetext{
51 Rossi (2018: 4-5); con la expresión «nueva» ronda, la autora quiere referirse al anterior período de tensión entre los dos tribunales con ocasión del célebre asunto Taricco.

52 Por ejemplo, Conti (2018: 291 y ss.).

53 Sentencia del TJUE, sección I, de 20 de diciembre de 2017, Global Starnet.

54 Consejo de Estado, sección IV, Auto de 1 de junio de 2016, n. 2334.

55 Véase el apartado II.2 de este trabajo.
} 
Esto condujo a la formación de un sólido ménage a dos, con la consecuencia de que, posteriormente, resultó complicado transformarlo en un ménage a $\operatorname{tres}^{56}$, cuando la Corte quiso entrometerse en esa relación de confianza entre los jueces nacionales y el TJUE a fin de asegurar su rol de guardián de los derechos fundamentales.

En estas coordenadas, la reacción más «esperada» era, sin duda, la del Tribunal de Casación. Una parte de la doctrina lo había exhortado a ser «valiente» y plantear ante el Tribunal de Luxemburgo una cuestión prejudicial que tuviera como objeto la nueva jurisprudencia de la Corte Constitucional ${ }^{57}$.

El Tribunal de Casación no adoptó una postura unívoca, sino todo lo contrario.

En el caso más conocido y comentado, el Tribunal de Casación decidió seguir las indicaciones de la Corte Constitucional y, al tener dudas sobre la conformidad de la legislación nacional tanto con la Constitución como con la Carta DFUE, planteó una cuestión de legitimidad constitucional ${ }^{58}$. En realidad, el Tribunal de Casación tuvo también dudas respecto de si la nueva doctrina constitucional pudiera entrar en contradicción con la jurisprudencia del Tribunal de Justicia. Se coloca, por tanto, al tribunal nacional de última instancia (como la Casación) ante la disyuntiva de o bien seguir la jurisprudencia constitucional o bien respetar la obligación de plantear una cuestión prejudicial a la que se refiere el art. 267 TFUE. El juez a quo decidió respetar el obiter de la Corte, pero aprovechó la ocasión para pedirle una «aclaración» sobre cómo resolver la disyuntiva; aclaración que algunos han interpretado como una advertencia en toda regla al juez constitucional (Randazzo, 2018: 371), en el caso de que este decidiera resolver el asunto con una decisión desestimatoria. En el auto de planteamiento de la cuestión de inconstitucionalidad,

56 Esta expresión ha sido utilizada también por Rossi (2018: 2).

57 Conti (2018: 293). Ruggeri (2018: 82) ha definido como una actuación "no valiente» la decisión con la que el Tribunal de Casación resolvió plantear una cuestión de constitucionalidad, siguiendo las indicaciones de la Corte Constitucional.

58 Auto de la Corte de Casación, de 16 de febrero de 2018, n. ${ }^{\circ} 3831$. Para resolver el caso, la Corte Constitucional, con muy buen criterio, como se evidenciará también en las conclusiones, ha planteado una cuestión prejudicial al TJUE a través del Auto de 10 de mayo de 2019, n. ${ }^{\circ} 117$, demostrando la utilidad de su nueva jurisprudencia para incrementar y fomentar un virtuoso y eficaz diálogo entre tribunales. A fecha de aceptación del presente trabajo, el Tribunal de Luxemburgo no ha emitido la sentencia de respuesta al caso.

Para un pronóstico de las posibles respuestas a la solicitud de aclaración, puede consultarse Vernuccio (2018: 16-17). 
en efecto, la Casación ilustra acerca de cuáles serían las dudas que cabría plantear ante el TJUE. No obstante, y para así respetar las nuevas «sugerencias» del Constitucional contenidas en la Sentencia 269/2017, la Casación aceptó trasladar el caso ante la Corte Constitucional59.

Pero en otros casos la Casación ha elegido un camino diferente. En algunas decisiones, el obiter dictum de la Corte no ha sido atendido y no se ha admitido su eficacia impeditiva respecto al planteamiento de la cuestión prejudicial. Y, aún más, hay supuestos en los que la Casación ha inaplicado directamente la legislación nacional por considerarla contraria a la Carta ${ }^{60}$, sin necesidad de plantear la cuestión de inconstitucionalidad ni la prejudicial ante el TJUE.

\section{LAS PUNTUALIZACIONES DE LA CORTE CONSTITUCIONAL A LA SENTENCIA 269/2017 A TRAVÉS DE SU JURISPRUDENCIA POSTERIOR}

Además de la invitación del Tribunal de Casación, la doctrina italiana insistió en la necesidad de que la Corte aclarase o puntualizase su nueva doctrina ${ }^{61}$.

La Corte no tardó en complacer a unos y otros, emitiendo hasta cuatro decisiones aclaratorias durante los primeros seis meses de 2019.

La primera de ellas fue la Sentencia $20 / 2019^{62}$, en la que la Corte resolvió una cuestión de inconstitucionalidad cuyo objeto tenía que ver con principios reconocidos tanto en la Constitución italiana como en la Carta (en concreto, el derecho a la privacidad y el principio de publicidad y transparencia de la actividad de los poderes públicos). El caso presentaba una peculiaridad añadida: la norma de derecho interno podía entrar igualmente en contradicción con una directiva UE sobre la que el Tribunal de Justicia ya se había pronunciado, sosteniendo que esta contenía previsiones directamente aplicables, aunque expresivas de principios. Así pues, el juez ordinario habría podido

59 Estas mismas observaciones las expresa también Tega (2018a).

60 Sentencias de la Corte de Casación de 17 de mayo de 2018, n. ${ }^{\circ}$ 12108, y de 21 de febrero de 2018, n. ${ }^{\circ} 4223$.

En doctrina, sobre los efectos del obiter dictum de la Sentencia 269/2017, véanse también Cosentino (2018), Rossi (2018: 4 y ss.), Amalfitano (2019b: 25 y ss.), Massa (2019), Mastroianni (2018: 32 y ss.) y Leone (2020).

61 Véanse, entre otros, Randazzo (2018: 372-374), Comazzetto (2018: 30 y ss.) y Rossi (2018: 11).

62 Sentencia de la Corte Constitucional de 21 de febrero de 2019, n.o 20. 
inaplicar directamente la normativa interna. No obstante, el órgano jurisdiccional sostuvo que le resultaba imposible identificar una regulación directamente aplicable, pues los principios que entraban en juego eran de carácter general e implicaban una ponderación de derechos, bienes y valores constitucionales, lo cual aconsejaba un pronunciamiento de la Corte.

La Corte respondió reiterando la doctrina de la Sentencia 269/2017, pero añadiendo cuatro valiosas puntualizaciones.

La primera reclama que los jueces, en caso de que una misma normativa suponga una violación conjunta de la Constitución y de la Carta, recurran, en primer lugar, a la jurisdicción constitucional. La Corte, sea como fuere, no impone dicha solución, sino que, más bien, se dirige a los jueces en términos de «oportunidad»; con su habitual tono "diplomático y cortés» ${ }^{63}$, el Constitucional deja la elección al juez, que habrá de dar prioridad al control de constitucionalidad solo en el caso de estar convencido de la verdadera utilidad de este «orden de aparición en la escena».

La segunda alude a la cuestión del «objeto» de la prioridad, pues en el caso se denunciaba la supuesta violación de una directiva UE, y no de la Carta. La Corte sostiene que la solución sugerida en la Sentencia 269/2017 debía considerarse confirmada también en este caso, ya que los principios contenidos en la directiva tienen una conexión peculiar con las disposiciones de la Carta en un doble sentido: por un lado, porque "proporcionan una especificación o desarrollo» de esas, pero también, e incluso a la inversa, porque «han constituido un "modelo" para esas normas [las de la Carta] y, por tanto, tienen evidentemente su misma naturaleza, tal como se expresa en las Explicaciones de la Carta» ${ }^{64}$.

La tercera puntualización se centra en el aspecto más discutible del obiter dictum de la 269/2017, esto es, la aportación de la Corte Constitucional respecto de la doctrina Melki, al añadir las palabras "por otras razones» a las afirmaciones del TJUE de 2010. Gran parte de la doctrina había entendido que, con tal inciso, la Corte había querido limitar la posibilidad de que el juez ordinario pudiera directamente inaplicar la norma objeto de un previo control de constitucionalidad terminado con una

63 Utilicé estos términos para definir el estilo usado por el Constitucional también describiendo el diálogo entre la Corte Constitucional y el TJUE con ocasión del célebre caso Taricco: Romboli, S. (2017: 34).

64 Esta parte de la decisión ha sido criticada por Ruggeri (2019b: 113 y ss.) y por Bronzini (2019: 3), que considera que de este modo la Corte ha realizado una suerte de «macroscópico efecto extensivo» que intenta incluir también el derecho derivado entre los posibles objetos del control prioritario de constitucionalidad. 
sentencia declarativa de la constitucionalidad de esta misma o puenteara dicha decisión pasando por el Tribunal de Luxemburgo.

El Constitucional, entonces, revisa parcialmente su declaración anterior, especificando que el juez puede someter al Tribunal de Justicia «sobre la misma normativa, cualquier prejudicial que considere necesaria», negando cualquier impedimento que pueda derivarse del previo planteamiento de una cuestión de inconstitucionalidad y despejando, así, las dudas de buena parte de los comentaristas.

Con la cuarta y última aclaración, la Corte avanza (casi como si quisiera asegurar sus «buenas intenciones») que ella misma se pronunciará de manera prioritaria sobre la eventual lesión de un parámetro constitucional con la finalidad de contribuir a que los derechos fundamentales garantizados por el DUE y, en particular, por la Carta, se interpreten en armonía con las tradiciones constitucionales comunes de los Estados miembros, tal y como prescribe el art. 52.4 de la Carta.

Al mes siguiente, la Corte tuvo otra oportunidad de pronunciarse sobre la doble prejudicialidad con ocasión de otra cuestión de inconstitucionalidad ${ }^{65}$ en la que el presidente del Gobierno alegó la incompetencia de la Corte para pronunciarse sobre la presunta violación de la Carta. El juez constitucional afirmó su competencia para resolver esta tipología de asuntos y, por ende, para declarar la inconstitucionalidad de una ley por violación de las disposiciones de la Carta, todo esto después de plantear, si fuera necesario, una cuestión prejudicial al Tribunal de Justicia. Asimismo, el Constitucional aprovechó para volver sobre la interpretación del inciso "por otras razones», declarando que el juez ordinario puede plantear una cuestión prejudicial al TJUE «también después del control incidental de constitucionalidad de la ley», añadiendo esta vez que el órgano jurisdiccional podrá incluso «no aplicar» la norma nacional que considere contraria a la Carta, si considera que concurren los presupuestos necesarios.

Si con la Sentencia 20/2019 la Corte había acotado y reducido los efectos de la 269/2017 (afirmando que el juez puede plantear una cuestión ante el TJUE incluso después de la sentencia constitucional y por las mismas razones examinadas en ella), con la Sentencia 63/2019 estos efectos han sido definitivamente eliminados, a través del reconocimiento explícito de la posibilidad del juez de inaplicar la norma nacional que haya resistido al control de constitucionalidad. Este nuevo criterio ha sido recibido con entusiasmo por la doctrina, sobre todo por los que veían en la Sentencia 269/2017 un incumplimiento de las obligaciones de la Unión.

65 Resuelta con la Sentencia de la Corte Constitucional, de 21 de marzo de 2019, n.o 63. 
Otros dos pronunciamientos de la Corte merecen, finalmente, una breve consideración. En el primero, la Corte se limitó a confirmar su competencia para pronunciarse también sobre la violación de la $\mathrm{Carta}^{66}$, y más en el supuesto de que «el juez a quo lo solicitara ${ }^{67}$. El segundo es, sin duda, más relevante. La Corte afirmó claramente la voluntad de recurrir al Tribunal de Justicia toda vez que sea necesario aclarar el significado y los efectos de las disposiciones de la $\mathrm{Carta}^{68}$. Al mismo tiempo, reiteró que los jueces tienen libertad absoluta para plantear ellos mismos, incluso después de la sentencia constitucional, una cuestión prejudicial ante el Tribunal de Justicia y para inaplicar la norma nacional en contradicción con las disposiciones UE directamente aplicables. Por otro lado, la Corte sostuvo que la «concurrencia de remedios", a saber, la existencia simultánea de diferentes y variados instrumentos jurisdiccionales, permite que la Corte misma interprete los derechos fundamentales de la Carta, que corresponden a los de la Constitución, en armonía con las tradiciones constitucionales comunes a los Estados miembros, todo en un clima de leal colaboración para garantizar la máxima protección de los derechos en un contexto de tutela multinivel.

\section{LAS PERSPECTIVAS ACTUALES RESPECTO DE LAS RELACIONES ENTRE JURISDICCIONES}

A resultas de cuanto antecede, es evidente que la situación actual ante la que deberá actuar la jurisdicción ordinaria no permite una interpretación unívoca.

En primer lugar, el juez ordinario, ante una norma nacional con rango de ley que considera contraria tanto a la Carta DFUE como a la Constitución, puede decidir seguir la "sugerencia» de la Corte Constitucional y plantear antes una cuestión de inconstitucionalidad, o, por el contrario, optar por elevar una prejudicial ante el TJUE. Una vez tomada esta primera decisión, se abren otras diferentes posibilidades de actuación por el mismo juez ordinario, dependiendo de la respuesta del órgano jurisdiccional al que se ha dirigido de manera prioritaria.

66 Merece la pena precisar que en Italia la Corte Constitucional puede declarar inconstitucional una norma con rango de ley por violación de las obligaciones que derivan del ordenamiento supranacional, utilizando el art. 117.1 de la Constitución italiana como «norma interpuesta».

67 Sentencia de la Corte Constitucional, de 10 de mayo de 2019, n. ${ }^{\circ} 112$.

68 Auto de la Corte Constitucional, de 10 mayo de 2019, n.o 117. 
Si la situación ante la que se encuentra el juez ordinario es muy enrevesada o vidriosa, la de la jurisdicción constitucional es la opción más clara y menos problemática.

En primer lugar, conforme a la Sentencia 269/2017, la cuestión de inconstitucionalidad que tenga por objeto una presunta violación conjunta de la Constitución y de la Carta propuesta por un juez ordinario tendrá que considerarse admisible y el órgano jurisdiccional nacional ya no estará obligado a pasar de forma prioritaria por el Tribunal de Luxemburgo.

Recibida la cuestión, el Constitucional tendrá dos opciones: resolverla o plantear una cuestión prejudicial ante el TJUE en la que se solicite, si fuera necesario, la interpretación de las previsiones de la Carta.

El nuevo escenario que se abre a la jurisdicción constitucional italiana suscita, en cualquier caso, dudas e interrogantes.

Una de estas dudas concierne al reconocimiento de la Corte Constitucional como órgano judicial legitimado para plantear cuestiones prejudiciales ante el TJUE. Como es sabido, en Italia esta posibilidad ha sido avalada por la misma jurisprudencia constitucional desde el año 2008. Dado que el art. 137.3 de la Constitución italiana establece expresamente que «contra las decisiones de la Corte constitucional no se admite recurso alguno", el Constitucional tiene la condición de órgano jurisdiccional de última instancia. En consecuencia, la obligación de plantear una cuestión prejudicial debe aplicarse incluso a él, a menos que se den las condiciones establecidas por la jurisprudencia Cilfit (irrelevancia de la cuestión, acto claro o acto aclarado). Por consiguiente, si no se estuviera ante alguno de estos tres supuestos, la Corte Constitucional podría ser condenada, como sucedió recientemente con el Consejo de Estado francés ${ }^{69}$, por ser jurisdicción de última instancia y no haber planteado la cuestión ante el Tribunal de Luxemburgo.

En este contexto, se sugiere que la Corte Constitucional utilice de forma «generosa» la cuestión prejudicial ante el Tribunal de Justicia ${ }^{70}$.

69 Véase, al respecto, Fasone (2018), que comenta la decisión con la que el Tribunal de Justicia UE (Sentencia de 4 de octubre de 2018, Comisión c. Francia, C-416/17) condenó al Consejo de Estado francés por apartarse de la jurisprudencia UE sin plantear una cuestión prejudicial, violando, así, la obligación ex art. 267.3 TFUE. Conti (2017b: 29) propone un supuesto hipotético en el que el Constitucional, al plantear la cuestión prejudicial, luego no quiera acatar sus contenidos; en un caso semejante, opina el autor, el juez ordinario podría volver a remitir el asunto al juez europeo.

70 De esta opinión, además de quien escribe: Catalano (2019: 32), Massa (2019) y Rossi (2018: 14). Vitale (2019: 14) confía en que la Corte Constitucional tenga «la humildad para dirigirse ella misma en vía prejudicial a los jueces de Luxemburgo». 


\section{CONSIDERACIONES CONCLUSIVAS SOBRE LOS EFECTOS DEL NUEVO ORDEN DE PRIORIDAD EN EL DIÁLOGO ENTRE TRIBUNALES}

Tomando en consideración este repaso de la jurisprudencia constitucional italiana en materia de «doble prejudicialidad», parece oportuno plantearse un interrogante: ¿qué queda del obiter dictum de la Sentencia 269/2017, después de todos los vuelcos interpretativos?, ¿ «mucho ruido para nada» ${ }^{71}$ ?

A mi juicio, la respuesta ha de ser necesariamente negativa. El obiter, sus interpretaciones doctrinales y las posteriores aclaraciones de la Corte Constitucional ponen de manifiesto un debate científico apreciable y hasta un sugestivo diálogo de tribunales en torno a las relaciones entre el derecho nacional y el derecho de la UE.

No puede negarse que la Corte haya apostado por el carácter prioritario del control incidental de constitucionalidad frente a la cuestión prejudicial, en todo supuesto en el que el juez tenga, al mismo tiempo, sobre una misma norma nacional, una duda de constitucionalidad y de conformidad con la Carta DFUE. El revirement jurisprudencial tendrá, con toda probabilidad, unos efectos positivos para el diálogo entre las jurisdicciones nacionales y la supranacional y para la tutela multinivel de los derechos.

Las «sugerencias» de la Corte Constitucional no tenían el propósito - y tampoco tendrán el efecto- de trastocar el sistema de «jerarquías» entre la Corte Constitucional y el TJUE, en el sentido de querer abrir un nuevo conflicto entre las dos jurisdicciones para declarar cuál de las dos debe salir vencedora en caso de que mantengan distintas interpretaciones del contenido esencial de un derecho fundamental reconocido simultáneamente en la Constitución y en la Carta. Más bien, podría decirse que la Corte ha querido modificar el orden de aparición en escena de los participantes en el diálogo, entrometiéndose en una conversación «a dos» (juez ordinario y TJUE) y, así, transformarla en una conversación «a tres» (juez ordinario, Corte Constitucional y TJUE), cuando esta tenga que ver con la interpretación de los derechos fundamentales, asegurándose ser escuchada y participando, así, activamente en el desarrollo y la mejora de los contenidos que entrarán a formar parte de las tradiciones constitucionales comunes en la Unión Europea.

Como ha reiterado muy recientemente la letrada del Tribunal de Justicia de la UE Iglesias Sánchez ${ }^{72}$, el diálogo directo entre los tribunales constitucionales y

71 Esta locución es utilizada por Amalfitano (2019a: 7 y ss.).

72 Las afirmaciones de Iglesias Sánchez (2020) fueron pronunciadas en ocasión de las jornadas La aplicación de la Carta de los Derechos Fundamentales de la Unión Europea en España a los 10 años de su entrada en vigor, celebradas en la Facultad de Derecho 
el Tribunal de Luxemburgo a través de cuestiones prejudiciales en torno a la interpretación de los derechos reconocidos en la Carta es absolutamente fundamental y necesario para que estos órganos jurisdiccionales colaboren en la exteriorización, consolidación y, en suma, enriquecimiento de las tradiciones constitucionales comunes.

De esta forma la Corte Constitucional se convierte en la jurisdicción de última instancia a nivel nacional, y está absolutamente legitimada para adoptar un papel protagonista en ese diálogo. No obstante (y por consiguiente), tendrá que respetar las reglas que el ordenamiento de la Unión impone al juez de última instancia (en caso de duda de conformidad del derecho interno con el DUE, y al no estar ante una de las excepciones aludidas en la doctrina Cilfit). Lo más adecuado será, pues, que la Corte plantee siempre la cuestión prejudicial ante el Tribunal de Justicia y "dialogue» sobre la interpretación conforme de la normativa nacional a la Carta (y a la Constitución). Es más, resulta crucial que el órgano encargado de representar una determinada situación normativa nacional ante el TJUE sea el tribunal constitucional del Estado, máxime cuando entran en juego derechos, principios y valores constitucionales. Las Cortes constitucionales, como demuestra el célebre caso Taricco (Amalfitano, 2019b: 24-25), son los actores más idóneos y seguramente los que tienen más autoridad para defender los principios fundamentales nacionales ante la jurisdicción supranacional, mucho más que los jueces y tribunales ordinarios ${ }^{73}$.

de la Universidad Pompeu Fabra, Barcelona (13-14 de febrero de 2020), cuyas actas están en prensa. Estas mismas consideraciones pueden encontrarse en la doctrina europea más «clásica»; véase, por ejemplo, Rodríguez Iglesias y Valle Gálvez (1997).

73 La doctrina mayoritaria se ha manifestado a favor de la opción de que la Corte exprese la "primera palabra» en este diálogo. En este sentido, puede verse, entre otros, Scaccia (2018: 2), que afirma que «la necesidad de armonizar la interpretación de los derechos de "acuñación europea" con los homólogos derechos reconocidos en la Constitución se garantiza de manera más efectiva e inmediata si los jueces llamados a proteger la tradición constitucional interna se pronuncian primero sobre el derecho en cuestión en lugar de intervenir [...] de manera posterior con el remedio extremo y áspero de los contra-límites»; pueden consultarse también los trabajos de Tega (2018b: 197 y ss.) y Guazzarotti (2017: 1-3).

De opinión opuesta, Gallo (2019: 233-234), según el cual sostener que los tribunales constitucionales tienen siempre la primera palabra sobre contenido, naturaleza, alcance y efectos de los derechos fundamentales reconocidos en la Carta significa impedir ya en origen el "salto cualitativo", en términos de protección del derecho paradójicamente invocado por los partidarios de la primera palabra a la Corte Constitucional. 
Llegados a este punto, ¿es oportuno hablar de una evolución de la jurisprudencia constitucional o, como han planteado algunos, de una verdadera revolución? Entiendo que resulta más razonable hablar del revirement como de una «inversión de marcha oportuna $»^{74}$. Las matizaciones de la Corte han de considerarse un paso importante para la realización del objetivo que todas las jurisdicciones involucradas en el «diálogo» persiguen: desterrar la "guerra entre los tribunales» y concentrar los esfuerzos en lograr una tutela más eficaz de los derechos fundamentales. En tal sentido, la Corte alude a la trascendencia de la "concurrencia de remedios», esto es, de la existencia simultánea de diferentes y variados instrumentos jurisdiccionales que permiten a los tribunales interpretar los derechos fundamentales (de la Carta y de la Constitución) conforme a las tradiciones constitucionales comunes de los Estados miembros.

Una prueba más de la difusión a nivel internacional (o, por lo menos, europeo) de esta reflexión o "conciencia» colectiva es la reciente entrada en vigor del Protocolo n. ${ }^{\circ}$ XVI del Convenio Europeo de Derechos Humanos (CEDH), que añade, como es sabido, otro instrumento prejudicial de interpretación de los derechos ante el Tribunal Europeo de Derechos Humanos (TEDH) ${ }^{75}$.

Claro está que un sistema jurídico en el que se desarrollan "conversaciones» tan concurridas puede manifestar dificultades en su funcionamiento. El juez ordinario, por ejemplo, constituye claramente el actor más sujeto a la posibilidad de desorientarse en un escenario confusional en el que proliferan instrumentos y jurisdicciones. También por eso (además de las razones ya detalladas en las páginas anteriores), la Corte Constitucional ha considerado necesario proponer un nuevo orden de comparecencia, evidenciando la necesidad de su implicación en el diálogo: el juez nacional podrá plantear la cuestión constitucional antes que la prejudicial eurounitaria (si sigue la sugerencia de la Corte), o elegir el orden inverso, cuando haya una duda de interpretación relativa a la Carta $\mathrm{DFUE}^{76}$.

74 Esta es la postura, entre otros, de Catalano (2019), a la que adhiero.

75 Para un estudio detallado de este instrumento y algunas reflexiones sobre su utilidad en el diálogo entre tribunales, pueden verse, por ejemplo, López Guerra (2014) y Romboli, S. (2020).

76 En opinión de Amalfitano (2019a: 24), el órgano jurisdiccional podrá incluso plantear simultáneamente las dos prejudiciales, para así sumar las ventajas del control concentrado a las del control difuso y conciliar las exigencias de tutela con la de certeza del derecho (sacrificando el requisito de la relevancia). La existencia de diferentes procedimientos puede, paradójicamente, determinar una menor protección efectiva de los derechos, de modo que intentar aprovechar ambos procedimientos es casi, como han afirmado Cruz Villalón y Requejo Pagés (2015), «un imperativo del sentido de la justicia». 
Las ventajas de la participación de la Corte Constitucional en el «diálogo a tres» (y apareciendo, como orden, entre el juez nacional y el TJUE) han resultado, en mi opinión, evidentes en estas páginas. Claro está que también el juez ordinario tiene que estar convencido de la oportunidad, para una eficaz protección de los derechos, de la opción de interpelar de manera prioritaria a la Corte Constitucional. La Corte, por su parte, debe utilizar bien su participación, a saber, tendrá que mostrarse abierta al diálogo, manteniendo una conducta al mismo tiempo humilde, de autocontención, pero firme. Humilde en el sentido de procurar, siendo la jurisdicción de última instancia a nivel nacional, plantear siempre que sea oportuno la cuestión prejudicial ante el TJUE, detallando su interpretación del principio, valor o derecho constitucional que suscita la duda del juez a quo ${ }^{77}$. Y habrá de demostrar su buena predisposición en la recepción de la respuesta del TJUE, para fomentar el diálogo en la creación de las tradiciones constitucionales comunes. No obstante, podrá y hasta deberá mantenerse firme en sus razonamientos cuando se refieran al plano de la constitucionalidad. $\mathrm{Si}$, después de la "conversación a tres», el Constitucional siguiera convencido de la inconstitucionalidad de dicha norma, tendrá que proceder a la declaración de nulidad. Ello no conllevará violación de las obligaciones con la Unión ${ }^{78}$, sino que tendrá los efectos positivos que derivan de la eliminación erga omnes de la norma nacional, reforzando, así, el principio de certeza del derecho $^{79}$. No obstante, si el Tribunal de Justicia declarara la norma nacional en contradicción con el DUE, la Corte Constitucional tendría que respetar las obligaciones que derivan del ordenamiento supranacional, según el art. 117 de la Constitución italiana, y, por lo tanto, declarar inconstitucional la norma en cuestión.

\section{Bibliografía}

Amalfitano, C. (2019a). Il dialogo tra giudice comune, Corte di giustizia e Corte costituzionale dopo l'obiter dictum della sentenza n. 269/2017. Osservatorio sulle fonti, 2, 1-35.

77 Esta ha sido exactamente la actuación de la Corte con ocasión del planteamiento del Auto, ya recordado antes, de 10 de mayo de 2019, n. ${ }^{\circ} 117$, después de que la Corte de Casación elevara una duda de legitimidad constitucional con el Auto de 16 de febrero de 2018, n. ${ }^{\circ}$ 3831. Ahora toca esperar la respuesta del TJUE, confiando que el Tribunal esté dispuesto a seguir adelante con el diálogo.

78 En efecto, la de la Corte no debería considerarse una actuación en contra de las indicaciones del TJUE, sino, simplemente, una aplicación y consecuencia del mantenimiento de la "concepción dualista» a la que se hacía referencia al principio de este trabajo.

79 De esta opinión también, entre otros, Ruggeri (2019c: 56 y ss.). 
- (2019b). Rapporti di forza tra Corti, sconfinamento di competenze e complessivo indebolimento del sistema Ue? La legislazione penale, 1-40.

Anzon, A. (2018). La Corte riprende il proprio ruolo nella garanzia dei diritti costituzionali e fa un altro passo avanti a tutela dei "contro limiti». Forumcostituzionale.it, 1-40.

Barbera, A. (2018). La Carta dei diritti: per un dialogo fra la Corte italiana e la Corte di giustizia. Quaderni costituzionali, 149-171.

Bronzini, G. (2019). La sentenza n. 20/2019 della Corte costituzionale italiana verso un riavvicinamento all'orientamento della Corte di giustizia? Questione giustizia online, 8-3-2019, 1-35.

Cartabia, M. (1997). Considerazioni sulla posizione del giudice comune di fronte a casi di «doppia pregiudizialità», comunitaria e costituzionale. Il Foro italiano, V, 222-254.

- (2006). La Corte costituzionale italiana e il rinvio pregiudiziale alla Corte di giustizia europea. En N. Zanon (coord.). Le Corti dell'integrazione europea e la Corte costituzionale italiana (pp. 101-104). Napoli: Edizioni scientifiche italiane.

Caruso, C. (2017). La Corte costituzionale riprende il «cammino comunitario»: invito alla discussione sulla sentenza n. 269 del 2017. Forumcostituzionale.it, 18-12-2017, 1-40.

Catalano, S. (2016). La question prioritarie de constitutionalité in Francia: analisi di una riforma attesa e dei suoi significati per la giustizia costituzionale italiana. Napoli: Edizioni Scientifiche Italiane.

— (2019). Doppia pregiudizialità: una svolta 'opportuna' della Corte costituzionale. Federalismi.it, 10, 1-40.

Cerri, A. (2013). La doppia pregiudizialità in una innovativa decisione della Corte. Giurisprudenza costituzionale, 2897-2934.

Comazzetto, G. (2018). Cronaca di una svolta annunciata: doppia pregiudizialità e dialogo tra Corti, a un anno dalla sentenza n. 269/2017. Federalismi.it, 20, 1-40.

Conti, R. (2017a). La Cassazione dopo Corte cost. n. 269/2017. Qualche riflessione, a seconda lettura. Forumcostituzionale.it, 28-12-2017, 1-34.

- (2017b). An, quomodo e quando del rinvio pregiudiziale alla Corte di giustizia quando è 'in gioco' la Carta dei diritti fondamentali UE. Riflessioni preoccupare dopo Corte cost. n. 269/2017 e a margine di Cass. n. 3831/2018-. Giudicedonna.it, 4, 1-35.

- (2018). Qualche riflessione, a terza lettura, sulla sentenza n. 269/2017. Rivista Diritti Comparati, 1, 291-331.

Cosentino, A. (2018). Il dialogo fra le Corti e le sorti (sembra non magnifiche, né progressive) dell'integrazione europea. Questione giustizia, 1-28.

Cozzi, A. (2018). Diretta applicabilità e sindacato accentrato di costituzionalità relativo alla violazione della Carta europea dei diritti fondamentali. Forumcostituzionale.it, 1-2-2018, 1-38.

Cruz Villalón, P. y Requejo Pagés, J. L. (2015). La relación entre la cuestión prejudicial y la cuestión de inconstitucionalidad. Revista de Derecho Comunitario Europeo, 50, 173-194.

Fasone, C. (2018). Violazione dell'obbligo di rinvio pregiudiziale e ricorso per inadempimento: verso un sistema di giustizia costituzionale "composito" nell'Unione. www.diritticomparati.it, 3-12-2018, 1-40. 
Ferreres Comella, V. (2011). El problema del «doble vicio» en que pueden incurrir las leyes nacionales: infracción de la Constitución e infracción del Derecho de la Unión Europea. A propósito del caso Melki. Actualidad Jurídica Uría Menéndez, 28, 57-61.

Gallo, D. (2019). Efficacia diretta del diritto Ue, procedimento pregiudiziale e Corte costituzionale: una lettura congiunta delle sentenze n. 269/2017 e 115/2018. Rivista AIC, 1, 228-252.

Ghera, F. (2000). Pregiudiziale comunitaria, pregiudiziale costituzionale e valore di precedente delle sentenze interpretative della Corte di giustizia. Giurisprudenza costituzionale, 1193-1234.

- (2009). La Corte costituzionale e il rinvio pregiudiziale dopo le decisioni n. 102 e 103 del 2008. Giurisprudenza costituzionale, 1315-1356.

Giovannetti, T. y Passaglia, P. (2014). La Corte ed i rapporti tra diritto interno e diritto sovranazionale. En R. Romboli (dir.). Aggiornamenti in tema di processo costituzionale (2011-13) (pp. 401-451). Torino: Giappichelli.

Guazzarotti, A. (2017). Un «atto interruttivo dell'usucapione» delle attribuzioni della Corte costituzionale? In margine alla sentenza n. 269/2017. Forumcostituzionale.it, 18-122017, 1-12.

Iglesias Sánchez, S. (2020). España y la Carta: su lenta difusión hacia un impacto real. Ponencia presentada en las jornadas La aplicación de la Carta de los Derechos Fundamentales de la Unión Europea en España a los 10 años de su entrada en vigor, celebradas en la Facultad de Derecho de la Universidad Pompeu Fabra, Barcelona, 13-14 de febrero de 2020 [en prensa].

Leone, S. (2020). La Corte costituzionale italiana riafferma la propria centralità nella tutela dei diritti rispetto al circuito giudici nazionali-giudici sovranazionali. En A. Pérez Miras et al. (dirs.) y C. Montesinos Padilla (coord.). Setenta años de Constitución italiana y cuarenta años de Constitución Española. Vol. II. Derechos fundamentales (pp. 99-117). Madrid: Centro de Estudios Políticos y Constitucionales; Boletín Oficial del Estado.

López Guerra, L. M. (2014). Los Protocolos de reforma n. ${ }^{\circ} 15$ y 16 al Convenio Europeo de Derechos Humanos. Revista Española de Derecho Europeo, 49, 11-29.

Losana, M. (2014). La Corte costituzionale e il rinvio pregiudiziale nei giudizi in via incidentale: il diritto costituzionale (processuale) si piega al dialogo tra le corti. Rivista Aic, 1, 232-267.

Malfatti, E. (2015). I "livelli» di tutela dei diritti fondamentali nella dimensione europea. Torino: Giappichelli.

Massa, M. (2019). Dopo la «precisazione». Sviluppi di Corte cost. n. 269/2017. Osservatorio delle fonti, 2, 1-40.

Marti, G. (2010). CJUE, gde ch., 22 juin 2010, Melki et Abdeli, aff. jointes C-188 et 189/10. Revue des Affaires Europeennes, 4, 889-904.

Mastroianni, R. (2018). Da Taricco a Bolognesi, passando per la ceramica Sant'Agostino: il difficile cammino verso una nuova sistemazione del rapporto tra Carte e Corti. Osservatorio sulle fonti, 1, 1-37.

Morrone, A. (2019). Suprematismo giudiziario. Spunti su sconfinamenti e legittimazione della Corte costituzionale. Quaderni costituzionali, 39 (2), 251-290. 
Onida, V. (2008). Nuove prospettive per la giurisprudenza costituzionale in tema di applicazione del diritto comunitario. En Diritto comunitario e diritto interno (pp. 47-79). Milano: Giuffrè.

Piccone, V. (2018). A prima lettura della sentenza della Corte di cassazione n. 4223 del 21 febbraio 2018. L'interpretazione conforme come strumento di «sutura» post Corte costituzionale n. 269/2017. Rivista di Diritto Comparato, 1, 327-359.

Randazzo, B. (2018). L'inversione della «doppia pregiudizialità» alla prova. Giornale di Diritto Amministrativo, 3, 371-403.

Repetto, G. (2016). Rinvio alla Corte di giustizia Ue e doppia pregiudizialità nei recenti orientamenti della Corte costituzionale. En Liber amicorum in onore di Augusto Cerri (pp. 659-698). Napoli: Editoriale scientifica.

- (2017). Concorso di questioni pregiudiziali (costituzionale ed europea), tutela dei diritti fondamentali e sindacato di costituzionalità. Giurisprudenza costituzionale, 2955-2987.

Rodríguez Iglesias, G. C. y Valle Gálvez, J. A. (1997). El Derecho Comunitario y las relaciones entre el Tribunal de Justicia de las Comunidades Europeas, el Tribunal Europeo de Derechos Humanos y los Tribunales Constitucionales nacionales. Revista de Derecho Comunitario Europeo, 2, 239-376.

Romboli, R. (2017). Il giudizio di costituzionalità delle leggi in via incidentale. En R. Romboli (dir.). Aggiornamenti in tema di processo costituzionale (2014-2016) (pp. 35-147). Torino: Giappichelli.

- (2018). Dalla «diffusione» all'«accentramento»: una significativa linea di tendenza della più recente giurisprudenza costituzionale. Foro italiano, I, 219-236.

(2020). Uno sguardo al futuro del costituzionalismo. En A. Pérez Miras et al. (dirs.) y S. Romboli (coord.). Setenta años de Constitución italiana y cuarenta años de Constitución Española. Vol. I. Balances y perspectivas en la Europa constitucional (pp. 99-122). Madrid: Centro de Estudios Políticos y Constitucionales; Boletín Oficial del Estado.

Romboli, S. (2017). "Los contra-límites en serio» y el caso Taricco: el largo recorrido de la teoría hasta la respuesta contundente pero abierta al diálogo de la Corte constitucional italiana. Revista de Derecho Constitucional Europeo, 28, 1-38.

- (2020). El rol del Protocolo n. 16 al CEDH en el diálogo entre Tribunales para una protección de los derechos más uniforme. Reflexiones al hilo de sus características y de la propuesta italiana de ratificación. En A. Pérez Miras et al. (dirs.) y C. Montesinos Padilla (coord.). Setenta años de Constitución italiana y cuarenta años de Constitución Española. Vol. II. Derechos fundamentales (pp. 41-61). Madrid: Centro de Estudios Políticos y Constitucionales; Boletín Oficial del Estado.

Rossi, L. S. (2018). Il «triangolo giurisdizionale» e la difficile applicazione della sentenza 269/17 della Corte costituzionale italiana. Federalismi.it, 16, 1-38.

Rousseau, D. (2012). La question prioritaire de constitutionnalité. Paris: Gazzette du Palais.

Ruggeri, A. (2017). Svolta della Consulta sulle questioni di diritto euro unitario assiologicamente pregnanti, attratte nell'orbita del sindacato accentrato di costituzionalità, pur se riguardanti norme dell'Unione self-executing (a margine di Corte cost. n. 269 del 2017). www.diritticomparati.it, 18-12-2017, 3.

- (2018). Una prima, cauta ed interlocutoria risposta della Cassazione a Corte cost. n. 269/2017. Consultaonline, 23-2-2018, 389-412. 
- (2019a). Ancora in tema di congiunte violazioni della Costituzione e del diritto dell'Unione, dal punto di vista della Corte di giustizia. En A. Ruggeri (dir.). «Itinerari» di una ricerca sul sistema delle fonti. Studi dell'anno 2018. Torino: Giappichelli.

- (2019b). La Consulta rimette a punto i rapporti tra diritto euro unitario e diritto interno con una pronunzia in chiaroscuro (a prima lettura di Corte cost. sent. n. 20 del 2019). Consultaonline, 25-2-2019, 113-132.

- (2019c). Rapporti interordinamentali e rapporti interistituzionali in circolo (scenari, disfunzioni, rimedi). Freedom, Security \& Justice: European Legal Studies, 2, 35-63.

Saiz Arnaiz, A. (2017). La interacción entre los tribunales que garantizan derechos humanos: razones para el diálogo. En A. Saiz Arnaiz; J. Solanes Mullor y J. E. Roa Roa. Diálogos Judiciales en el Sistema Interamericano de Derechos Humanos (pp. 29-43). Valencia: Tirant lo Blanch.

Scaccia, G. (2018a). L'inversione della 'doppia pregiudizialità' nella sentenza della Corte costituzionale n. 269 del 2017: presupposti teorici e problemi applicativi. www.forumcostituzionale, 25-1-2018, 1-39.

- (2018b). Giudici comuni e diritto dell'Unione europea nella sentenza della Corte costituzionale n. 269 del 2017. Osservatorio costituzionale AIC, 7-5-2018, 1-40.

Tega, D. (2018a). Il seguito in Cassazione della pronuncia della Corte costituzionale n. 269 del 2017: prove pratiche di applicazione. Questione giustizia, 12-3-2018, 1-32.

— (2018b). La sentenza n. 269 del 2017 e il concorso di rimedi giurisdizionali costituzionali ed europei. Quaderni costituzionali, 38 (1), 197-238.

- (2019). Lavori in corso. Le questioni in materia di diritti fondamentali tra incidente di costituzionalità e rinvio pregiudiziale. Quaderni costituzionali, 39 (3), 615-642.

Vecchio, F. (2010). Il Trattato di Lisbona e le ipotesi di «doppia pregiudizialità»: differenti prospettive di tutela e pericoli di pronunce incoerenti. Giustizia amministrativa, 2, 63-92.

Vernuccio, S. (2018). La sentenza 269/2017: la Corte costituzionale di fronte alla questione dell'efficacia diretta della Carta di Nizza e la prima risposta del giudice comune (Cass. ord. 3831/2018). Osservatorio costituzionale AIC, 29-5-2018, 1-40.

Viganò, F. (2019). La tutela dei diritti fondamentali della persona tra Corti europee e giudici nazionali. Quaderni costituzionali, 39 (2), 481-502.

Vitale, G. (2019). I recenti approdi della Consulta sui rapporti tra Carte e Corti. Brevi considerazioni sulle sentenze nn. 20 e 63 del 2019 della Corte costituzionale. Federalismi.it., 10, 1-37. 